(C) 2017. This manuscript version is made available under the CC-BY-NC-ND 4.0 license http:// creativecommons.org/licenses/by-nc-nd/4.0/

NOTICE: this is the author's version of a work that was accepted for publication in Animal Behaviour. Changes resulting from the publishing process, such as peer review, editing, corrections, structural formatting, and other quality control mechanisms may not be reflected in this document. Changes may have been made to this work since it was submitted for publication. A definitive version was subsequently published in Animal Behaviour 76: 855-864. DOI: 10.1016/j.anbehav.2008.02.015

\title{
Association patterns and foraging behaviour in natural and artificial
}

\section{guppy shoals}

\author{
LESLEY J. MORRELL ${ }^{1}$, DARREN P. CROFT ${ }^{1,2}$, JOHN R.G. DYER ${ }^{1}$, BEN B. \\ CHAPMAN $^{1}$, JENNIFER L. KELLEY $^{3}$, KEVIN N. LALAND $^{4}$ \& JENS KRAUSE ${ }^{1}$ \\ ${ }^{1}$ Institute of Integrative and Comparative Biology, University of Leeds \\ ${ }^{2}$ College of Natural Sciences, School of Biological Sciences, University of Wales$$
\text { Bangor }
$$
5

(8)
${ }^{3}$ School of Biological, Earth and Environmental Sciences, University of New South Wales, Sydney ${ }^{4}$ School of Biology, University of St Andrews

Running head: Morrell et al: Social associations and foraging

\section{Correspondence:}

Darren Croft

College of Natural Sciences

School of Biological Sciences

Bangor University

Brambell Building

Deiniol Road

Bangor, Gwynedd

LL57 2UW

Email: darren_croft@hotmail.co.uk

\section{Postal addresses:}


35 LJ Morrell, JRG Dyer, BB Chapman, \& J Krause: Institute of Integrative and 36 Comparative Biology, LC Miall Building, University of Leeds, Leeds, LS2 9JT, UK 37 JL Kelley: Centre for Evolutionary Biology, Zoology Building, School of Animal 38 Biology (M092), The University of Western Australia, Nedlands, WA 6009, Australia 39 KN Laland: School of Biology, University of St Andrews, Bute Medical Building, 40 Queen's Terrace, St. Andrews, Fife, Scotland KY16 9TS 
Animal groups are often non-random assemblages of individuals that tend to be assorted by factors such as sex, body size, relatedness and familiarity. Laboratory studies using fish have demonstrated that familiarity among shoal members confers a number of benefits to individuals such as increased foraging success. However, it is unclear whether fish in natural shoals obtain these benefits through association with familiars. Here, we investigate whether naturally occurring shoals of guppies (Poecilia reticulata) are more adept at learning a novel foraging task than artificial (where shoal members were selected randomly by the authors) shoals. We used social network analysis to compare the structure of natural and artificial shoals and examine whether shoal organisation predicts patterns of foraging behaviour. We found that fish in natural shoals benefited from increased success in the novel foraging task compared with fish in artificial shoals. Individuals in natural shoals showed a reduced latency to approach the novel feeder, followed more, and formed smaller sub-groups compared to artificial shoals. Our findings show that fish in natural shoals do gain foraging benefits, and that this may be facilitated by a reduced perception of risk among familiarised individuals, and/or enhanced social learning mediated by following other individuals and small group sizes. Although the structure of shoals was stable over time, we found no direct relationship between shoal social structure and patterns of foraging behaviour.

Keywords: guppy, information, innovation, Poecilia reticulata, shoaling tendency, social learning 
Wild animal groups commonly display non-random patterns of social structure.

Within a species, individuals are known to associate on the basis of kinship (Ward \& Hart 2003, Silk et al. 2006), body size (Ward \& Krause 2001), parasite load (Krause \& Godin 1994), disease status (Behringer et al. 2006) and colour (McRobert \& Bradner 1998), resulting in groups that are assorted by phenotypic characteristics. These association patterns are thought to confer anti-predator benefits, such as a reduction in risk through predator confusion; and foraging benefits, such as reduced competition for resources (Krause \& Ruxton 2002). A further level of social organisation can arise when individuals preferentially associate with, or avoid, conspecifics based on previous interactions (Griffiths 2003).

78

Preferences for associating with familiars have been reported in a number of animal groups (e.g. mammals: Porter et al. 2001, birds: Senar et al. 1990, reptiles: Bull et al. 2000, insects: Clarke et al. 1995), but have been particularly well studied in shoaling fishes. These studies have revealed that associations based on familiarity occur both in the laboratory (e.g. Barber \& Ruxton 2000, Barber \& Wright 2001) and the field (Griffiths \& Magurran 1997a, reviewed in Griffiths 2003). A number of benefits to associating with familiars have been demonstrated, including enhanced predator escape responses (Chivers et al. 1995), reduced levels of aggression (fishes: Utne-Palm \& Hart 2000; birds: Temeles 1994), increased foraging success (reviewed in Krause \& Ruxton 2002, Griffiths 2003, Ward \& Hart 2003) and an elevated performance in learning tasks (Swaney et al. 2001, Galef \& Giraldeau 2001). 0 groups of individuals that are linked by stable interactions (Croft et al. 2004, 2006, 
93 Gero et al. 2005). However, the majority of work investigating the benefits of

94 familiarity has focused on groups of fish that are artificially familiarised in the

95 laboratory (by holding fish together in small groups for a period of two weeks or

96 more), and it is unclear whether wild (i.e. naturally assorted) shoals would gain the

97 same benefits. Wild shoals of fathead minnows (Pimephales promelas) show more

98 cohesive anti-predator behaviour than unfamiliar, laboratory-assembled shoals

99 (Chivers et al. 1995), but other putative benefits of familiarity have not yet been

100 studied in natural groups. Here, we investigate whether natural shoals of guppies

101 (Poecilia reticulata) benefit from enhanced foraging success, when compared to

102 artificial (laboratory-assembled) shoals. We used female guppies, as they display

103 greater within-shoal fidelity than males (Griffiths and Magurran 1998), are more

104 likely than males to exploit novel foods (Laland \& Reader 1999a), and learn new

105 foraging tasks more rapidly than males (Laland and Reader 1999b). We present the

106 shoals with a novel foraging task, consisting of a novel foodstuff hidden within a

107 feeder, and investigate the success of shoal members in completing the task.

108

Previous work with fishes has shown that foraging success and performance in

110 a novel learning task are influenced by social structure, specifically group size. For

111 example, individuals in larger groups are generally more successful at locating food

112 patches e.g. Pitcher et al. 1982), and learning to escape from a moving net (Brown \&

113 Warburton 1999) than individuals in smaller groups, but individuals in smaller groups

114 can locate food more quickly when the food is hidden (the conformity effect; Day et

115 al. 2001). The influence of familiarity on learning has been well studied: In fish,

116 individuals learn more successfully from familiar demonstrators than from unfamiliar

117 conspecifics (where familiar groups are created by holding individuals together in the 
118 laboratory over a period of time; Swaney et al. 2001, Ward \& Hart 2005), and in

119 birds, young learn how to handle a new food source more effectively from familiar

120 adults than from unfamiliar ones (Cadieu \& Cadieu 2004).

121

123

124

125

126

127

128 associations.

One method which is becoming increasingly useful for understanding associations and structure in animal populations is social network analysis (e.g. Croft et al. 2004, Lusseau \& Newmann 2004, Wolf 2005). Previous work on guppies using this approach has demonstrated that individuals have preferred associations (i.e. associations are non-random), even within small shoals of fish (Croft et al. 2004, 2006). We use a social networks approach to investigate the influence of social structure on the performance of guppies in a novel foraging task. To our knowledge, this is the first time these techniques have been used in this way. Firstly, we investigate differences in social structure between natural and newly-created artificial shoals, and success in the foraging task. Secondly, we investigate whether social association patterns are linked to patterns of foraging and information transfer within groups. We predict that the social structure of natural shoals will reflect the nonrandom associations occurring within them (Croft et al. 2006), and thus will differ from association patterns in artificial shoals, where individuals will be unfamiliar, and preferred associations will not have been established. We also predict that individuals in natural shoals will forage more successfully (Swaney et al 2001, Ward \& Hart 2005), and that within shoals, individuals will be more likely to foraging with and obtain social information from those shoal members with whom they have close 
144 Study Site and Holding Conditions

145 Fish were captured from the Arima River in the Northern Mountain Range of Trinidad

146 (within $500 \mathrm{~m}$ of Verdant Vale Village, $10^{\circ} 41^{\prime} \mathrm{N}, 61^{\circ} 17^{\prime} \mathrm{W}$ ) during May 2005,

147 between $09.00-16.00$ hours, using a $2 \mathrm{~m}$ beach seine. In our investigation we used

148 natural and artificial shoals of fish, each containing 8 adult females. Shoals of 8 were

149 chosen as being representative of natural shoal sizes (2-20 individuals; Croft et al.

150 2003a). Natural shoals $(\mathrm{N}=10)$ consisted of groups captured together in the wild, and

151 artificial shoals $(\mathrm{N}=10)$ were groups assembled in the laboratory from over 300 fish

152 (see below).

153

154 Natural shoals consisting of at least 10 individuals were captured from the

155 river in their entirety, any males were released back into the river and 8 females of a

156 similar body size (mean \pm SD size of females in natural shoals $=27.99 \pm 2.97 \mathrm{~mm}$ )

157 were selected from each shoal. The remaining fish were returned to the river. A shoal

158 of guppies was defined as individuals that occurred within 4 body lengths of each

159 other (Pitcher \& Parrish 1993). The 8 fish were kept together, isolated from other

160 shoals, and returned to the laboratory, where each shoal was placed in a large artificial

161 pool $\left(\right.$ diameter $=120 \mathrm{~cm}$, water depth $=5 \mathrm{~cm}$, water temperature $\left.=26^{\circ} \mathrm{C}\right)$, and allowed

162 to acclimatise for 24 hours.

163

164 The 10 artificial shoals were created by collecting over 300 females using 36

165 seine hauls from a 500m stretch of river. The fish were returned to the laboratory and

166 placed in an artificial pool (as above) for 24 hours to allow complete mixing. From

167 this population 80 individuals of similar body size (mean \pm SD size of females in 
artificial shoals $=28.09 \pm 4.07 \mathrm{~mm}$ ) were selected and assigned haphazardly to 10

169 shoals. Each shoal was then placed in a visually isolated pool for 24 hours, as above.

170 Body size did not differ significantly between fish in natural and artificial shoals

171 (independent samples t-test: $\mathrm{t}_{1,158}=-0.178, \mathrm{p}=0.859$ ), and there was no significant

172 different in within-shoal standard deviation between natural and artificial shoals

$173\left(\mathrm{t}_{1,18}=-1.437, \mathrm{p}=0.168\right)$. Unused fish were placed in two large outdoor pools, and all

174 test shoals were maintained on a diet of commercially available flake food, given

175 twice per day.

Female guppies do not have any natural markings that can be used for

178 identification purposes and thus individuals from all shoals were anaesthetised using

179 tricane methanesulfonate (MS222), and given individual identity marks using a visible

180 implant elastomer injected in the dorsal epidermis (a standard procedure for marking

181 fish: see Croft et al. 2003b). All fish recovered quickly from the anaesthetic, normal

182 swimming behaviour was quickly resumed, and no mortality was observed as a result

183 of the marking process. Previous work has demonstrated that the procedure does not

184 affect shoaling decisions in guppies (Croft et al. 2004). After marking, shoals were

185 allowed to acclimatise for $12-16$ hours before experimental procedures began. The

186 experimental protocol for each shoal consisted of 1) quantifying the social structure

187 and shoaling associations (see below), 2) introducing a novel foraging task to the pool

188 and observing the success of fish in completing the task, and 3) re-quantifying the

189 social structure. For each shoal, the three elements of the experimental protocol were

190 carried out sequentially, separated by periods of 10 minutes.

192 Quantifying Social Structure 

membership of sub-groups within the shoal once per minute over a 30 minute period

195 (Croft et al. 2004; Thomas et al. in press). Previous work has shown this to be a

196 sufficient time period to quantify the non-random social network structure of guppy

197 shoals (see Croft et al. 2004 online supplementary material). We defined an

198 association between two fish as occurring when the fish were positioned within four

199 body lengths of each other, a distance that falls within the range of inter-individual

200 distances most commonly observed in shoaling fishes in nature (Pitcher \& Parrish

201 1993). All fish in a sub-group were within 4 body lengths of at least one other

202 member of the group (thus, if fish $\mathrm{A}$ and $\mathrm{C}$ were 6 body lengths apart, but fish $\mathrm{B}$ was

203 positioned between them, then all were considered members of a single sub-group).

204 One observer sat motionless, close to the edge of the pool, and a second person was

205 positioned further back from the pool to record the observations relayed to them by

206 the observer.

208 Novel Foraging Task

209 Ten minutes after quantifying association patterns, we introduced a novel

210 foraging task to the experimental arena. The task consisted of a white, opaque, plastic

211 cylinder (the 'feeder', height $=85 \mathrm{~mm}$, diameter at base $=75 \mathrm{~mm}$, diameter at top $=$

$21268 \mathrm{~mm}$ ) with a 20x20mm entrance hole located in the lower wall. The feeder was

213 placed with its centre $30 \mathrm{~cm}$ from the edge of the pool closest to the observer, with the

214 entrance hole facing the observer. At the beginning of the trial, a pinch of freeze-dried

215 bloodworm (Chironomus spp.) was placed in the feeder, where it floated on the

216 surface of the water, but was constrained within the feeder. Any odour cues from the

217 bloodworm are likely to be well contained within the feeder (Laland, K.N., 
unpublished data). Bloodworm represents a high-protein food source, readily consumed by the fish, and similar food items are likely to make up part of their natural diet (Magurran 2005). As the bloodworm floated on the water surface, fish

221 feeding at the surface inside the feeder were not visible to fish outside the feeder.

Following the introduction of the feeder, we recorded the time taken and the

224 identity of the first fish to approach the feeder within four body lengths. After this 225 initial approach observations were made over a 30 minute period. The delay before 226 commencing the observation period ensured that the fish were settled following the 227 introduction of the feeder into the pool, and that they had identified the presence of 228 this novel object. Each time a fish entered the feeder, or fed on the bloodworm at the 229 surface, we recorded the time since the start of the observation period and the identity 230 of the fish.

After 30 minutes, we removed the feeder and any remaining bloodworm from 233 the pool using a fine-mesh dip net, and after a 10 minute settling period, we re234 quantified social structure and association patterns using the same procedure as above. 235 This allowed us to check whether social structure was stable over the time period of 236 the experiment. Previous work has demonstrated that in the wild guppies can move 237 between shoals very rapidly, changing shoals up to once per minute (Croft et al. 238 2003a), and that associations quantified using this method are based on active 239 preferences (Croft et al. 2004). The 30-minute time interval between the two measures 240 of (pre- and post-foraging task) social stability is therefore sufficient to allow ample 241 opportunity for individuals to move among groups. At the end of the experiment, fish 
were removed from the experimental arena and placed in large artificial outdoor

243 pools, isolated from the river system.

245 Data Analysis

246 Group Sizes and Social Stability

247 From our observations of association patterns prior to the foraging task (see

248 'Quantifying social structure', above) we calculated the number and size of sub-

249 groups occurring at each time interval (i.e. every minute for 30 minutes, yielding 30

250 observations of group size for each shoal). From these data, the mean group size was

251 calculated for every time interval and we calculated the median value for each shoal

252 independently. We compared the median group sizes of natural and artificial shoals

253 using a Mann-Whitney U test. For each shoal, we also calculated the mean

254 percentage of individuals that were present in groups of sizes 1 to 8 , over the 30

255 observations, to give frequency distributions of group sizes for natural and artificial

256 shoals.

To test whether shoal associations are stable over time (i.e. before and after the

259 foraging task), we created association matrices for each shoal, describing association

260 patterns before and after the foraging trial. We compared the two association matrices

261 (before and after the foraging task) for each shoal using Mantel Tests for matrix

262 correlations. Where appropriate, p-values were combined using Fisher's Omnibus

263 Test to examine patterns across shoals. Throughout, 'shoal' refers to all 8 individuals

264 in a pool, and 'group' is used when the shoal divides into sub-units. 
For each shoal, we calculated the proportion of times that each individual fish

267 was observed with each other fish (i.e. the proportion of times all possible pairs were

268 associated) during the observation period (association strength, AS). The mean of

269 these values gives an overall AS for each shoal, which is an additional measure of

270 shoal cohesion. To investigate the variation in association scores, we calculated the

271 coefficient of variation of the association strengths for each shoal. In each shoal, all

272 fish were observed together one or more times over the $30 \mathrm{~min}$ observation period,

273 giving fully interconnected social networks. As such, measures of social network

274 structure based on the presence or absence of interactions between individuals (such

275 as mean degree, path length and clustering coefficients; e.g. Newman 2003; Croft et

276 al. 2004) are not informative and therefore have not been calculated.

Patterns of Foraging

If individuals learn socially from one another, we predict that they are likely to

280 follow one another into the feeder. To investigate whether individuals solved the task 281 by following another individual, or entering the feeder alone, we identified events 282 where an individual first entered the feeder shortly after another individual. We used 283 three definitions of following: 5, 10 and 20 seconds, and all following events were 284 included. Thus, an individual that entered the feeder 4 seconds behind another would 285 be included in all three analyses, while an individual entering 14 seconds behind 286 another would only be included in the 20 second analysis. A definition of following 287 within 5 seconds represents a situation where individuals enter closely behind another 288 individual (within about 4 body lengths), and therefore could be considered members 289 of the same shoal (Pitcher and Parrish 1993). A definition of following within 20 290 seconds, on the other hand, allows for the possibility that individuals can observe 
another entering the feeder from some distance away, then approach and enter the

292 feeder themselves. In the most successful shoal, the total number of feeder entries

293 over the 30 minutes was 59. This means that on average, one fish fed every 30.5

294 seconds, a greater time interval than our longest following definition of 20 seconds.

295 Within a shoal type (natural or artificial) we corrected p-values using Benjamini and

296 Hochberg's (1995) method for false discovery rate (FDR) control. Adjusted p-values

297 are presented.

If individuals do follow one another into the feeder, rather than foraging

300 independently, we would predict that entries to the feeder to be more closely clustered 301 in time than would be expected by chance (i.e. the null hypothesis would be that 302 foraging events are independent of one another). To investigate whether this is the 303 case, we performed a randomisation test. We used only foraging events occurring 304 within the interquartile range of foraging times (i.e. the 'middle half' of the each trial)

305 to control for differences in response towards the feeder after it was placed in the 306 pool, and any effect of satiation or food depletion on foraging towards the end of the 307 trial. For each shoal, we calculated the total number of observed feeder entries and the 308 number of occasions on which the difference between one entry time and the 309 preceding one (the entry lag) was less than 5, 10 or 20 seconds (possible following

310 events). We then generated a random set of feeder entry times (within the time 311 available in the interquartile range), containing the observed number of feeder entries, 312 and calculated the number of times the entry lags were less than 5, 10 or 20 seconds.

313 This was repeated 999 times. We calculated the total number of randomisations where 314 the predicted number of following events was greater than or equal to the number 315 observed in the shoal, to give a conservative probability that entries were more 
316 clustered in time in the observed shoal than expected by chance (one-tailed test). This

317 was repeated for all 10 natural shoals, and the 6 artificial shoals where entry events

318 were observed.

We used a further randomisation technique to investigate whether individuals

321 that first entered the feeder by following a leader ('lead-follow pairs') were

322 significantly more highly associated with that individual than would be expected if

323 they learnt the task by following another individual at random. To control for

324 differences between shoals in overall levels of association, we calculated the total of

325 the association strengths of all lead-follow pairs for each shoal. We defined lead-

326 follow pairs as two fish that entered the feeder within 20 seconds of each other,

327 assuming that individuals followed the immediately preceding fish (i.e. if three

328 individuals enter closely in time, in the order A, B and then C, we assume that B

329 follows $\mathrm{A}$, and $\mathrm{C}$ follows $\mathrm{B}$ ). The 20 second rule only was used due to low numbers

330 of following events for other rules in some shoals. For each shoal, we then randomly

331 selected the same number of pairs as were observed in lead-follow events, and

332 summed their association strengths. This randomisation was repeated 999 times for

333 each shoal. We then calculated how many of the randomly generated pairs had a

334 higher sum of association indices than the observed pairs, generating a probability (p-

335 value) that the observed pairs were significantly more associated than random pairs

336 (one-tailed test).

RESULTS 
341 Shoals?

342 Grouping behaviour differed between natural and artificial shoals. The median group

343 size was significantly larger in artificial shoals than in natural shoals (Mann-Whitney

$344 \mathrm{U}: z=-3.659, N_{\text {natural }}=N_{\text {artificial }}=10, P<0.001$ ), and small groups were commonly

345 observed in shoals of naturally co-occurring fish, while larger groups were most

346 commonly found in artificial shoals (figure 1).

Natural shoals had a significantly smaller mean shoal association strength

349 (AS) than artificial shoals (Mann Whitney U: $z=-3.628, N_{\text {natural }}=N_{\text {artificial }}=10, P<0.001$;

350 figure 2a). Associations in natural shoals were also more variable than in artificial

351 shoals: the coefficient of variation in AS was higher in natural than in artificial shoals

352 (Mann Whitney U: $z=-3.175, N_{\text {natural }}=N_{\text {artificial }}=10, P=0.001$; figure $2 \mathrm{~b}$ ). Both natural

353 and artificial shoals thus showed variation in AS between pairs of individuals within a

354 shoal, giving us the opportunity to investigate patterns of learning in relation to

355 patterns of social structure.

After the feeder had been placed in the pool, fish from natural shoals

358 approached it significantly more rapidly than fish from artificial shoals (Mann

359 Whitney U: $z=-2.117, N_{\text {natural }}=N_{\text {artificial }}=10, P=0.035$; figure $3 \mathrm{a}$ ), and more fish from

360 natural than artificial shoals entered and fed from the feeder (entering the feeder:

361 Mann Whitney U: $z=-2.701, N_{\text {natural }}=N_{\text {artificial }}=10, P=0.007$; not shown, feeding: Mann

362 Whitney U: $z=-3.752, N_{\text {natural }}=N_{\text {artificial }}=10, P<0.001$; figure $3 \mathrm{~b}$ ). In all 10 of the

363 natural shoals at least three fish fed, successfully completing the task. In one shoal, all 
364 fish fed. In comparison, we observed feeding in only 5 of the artificial shoals, where a 365 maximum of three individuals fed.

Can Patterns of Association Predict Patterns of Foraging?

Patterns of association in the pre-foraging trial (first) social network were

369 significant predictors of association patterns in the post-foraging trial (second) social 370 network (network correlations analysed using Mantel Test for matrix correlations, $P$

371 values combined using Fishers Omnibus test: wild shoals, $F_{20}=63.45, P<0.001$,

372 Table 1a; random shoals, $F_{20}=35.64, P=0.02$ ). This suggests that associations are 373 stable over the time of the experiment, and all further analysis is based on pre374 foraging trial associations only.

Do individuals follow others?

We found strong evidence that entries to the feeder were more closely

378 clustered in time than would be expected by chance in both natural and artificial

379 shoals, regardless of the definition of following used (Natural shoals: 5 seconds:

$380 \quad F_{20}=83.989, \mathrm{p}<0.001 .10$ seconds: $F_{20}=84.011, \mathrm{p}<0.001 .20$ seconds $: F_{20}=54.200$,

$381 \mathrm{p}<0.001$. Artificial shoals: 5 seconds: $F_{12}=27.522, \mathrm{p}=0.006 .10$ seconds: $F_{12}=44.190$, $382 \mathrm{p}<0.001 .20$ seconds: $\left.F_{12}=46.207, \mathrm{p}<0.001\right)$. Fish in both natural and artificial shoals 383 are therefore more likely to enter the feeder together than might be expected if each 384 individual was foraging independently, suggesting that the guppies were foraging 385 socially. In natural shoals, the majority of fish first entered the feeder alone (using a 388 rule that individuals only followed if they entered the feeder within 5 seconds of 
another fish), rather than following closely behind another fish (Wilcoxon signed ranks test:: $z=-2.501, N=10, P=0.036$ figure 4$)$, but this was not the case in artificial shoals $(z=-2.014, N=10, P=0.123$, figure 4$)$. Using a 10 or 20 second rule, however, there was no difference in the number of individuals who first entered the feeder alone and the number that first entered the feeder by following another individual (Wilcoxon signed ranks test: 10 seconds: natural shoals: $z=-1.869, N=10, P=0.093$; artificial shoals: $z=-1.841, N=10, P=0.099 ; 20$ seconds: natural shoals: $z=-1.279$, $N=10, P=0.201$; artificial shoals: $z=-1.236, N=10, P=0.216$, figure 4). Using all rules, there were elevated numbers of individuals that solved the task by following in the natural compared to the artificial shoals (5 seconds: Mann Whitney U: $z=-2.282$, $N_{\text {natural }}=N_{\text {artificial }}=10, P=0.039,10$ seconds: Mann Whitney U: $z=-2.868$, $N_{\text {natural }}=N_{\text {artificial }}=10, P=0.008,20$ seconds: Mann Whitney U: $z=-3.032$, $\left.N_{\text {natural }}=N_{\text {artificial }}=10, P=0.008\right)$. As a proportion of the total number of individuals that successfully solved the task, there was a non-significant trend towards a higher proportion of individuals following in natural shoals. (20 seconds: Mann Whitney U: $\left.z=-1.810, N_{\text {natural }}=10 N_{\text {artificial }}=6, P=0.073\right)$.

\section{Do individuals follow close associates when first entering the feeder?}

We confined our analysis within shoal following patterns to natural shoals for two reasons. Firstly, in natural shoals, individuals may be predicted to follow familiar associates, and secondly, because successful foraging (and thus the opportunity to learn by following) occurred in only half of the artificial shoals. We found no evidence for higher associations in observed lead-follow pairs (using the 20 second rule, see methods for definition) than would be expected if individuals followed others 
413 at random (Table 1b; Fisher's omnibus test to combine $P$-values across shoals:

$\left.414 \quad F_{20}=17.205, P=0.639\right)$.

\section{Do individuals forage with close associates?}

417 Previous work has suggested that individual guppies that associate in one 418 context may also associate in another (Croft et al. 2006). We investigated whether 419 social associations before the foraging trial were significant predictors of associations

420 during the 30 minute foraging period. We again defined a pair of fish as being 421 associated during foraging when they entered the feeder within 20 seconds of one 422 another. If individuals forage with close associates more frequently than with distant 423 associates, we would predict a positive correlation between the social associations and 424 foraging associations. We used Mantel tests for matrix correlations, and found no 425 evidence to suggest that associations during foraging could be predicted by the social 426 structure before the task (Table 1c, p-values combined using Fisher's omnibus test: $\left.427 \quad F_{20}=27.93, P=0.111\right)$.

\section{DISCUSSION}

431 Foraging Success, Boldness, Familiarity and Social Conformity

432 This study demonstrates for the first time that naturally occurring fish have a foraging 433 advantage over randomly composed shoals. In natural shoals, more individuals 434 successfully fed from the feeder than in artificial shoals, thus benefiting from 435 enhanced foraging success. Whilst a number of factors may have influenced the 436 success of natural shoals, our results suggest three plausible explanations: (1) a risk 437 perception hypothesis - differences in the perception of danger, resulting in greater 
risk-prone or bold behaviour in the natural shoals and more risk-averse or shy behaviour in the artificial shoals; (2) a social learning hypothesis - elevated levels of following and reduced effects of conformity in natural compared to artificial shoals; and (3) a time trade-off hypothesis - differences in the prioritisation of foraging and establishing social ties, resulting in reduced foraging motivation in artificial compared to natural shoals.

Several researchers have suggested that the perception of danger (resulting in risk-averse or shy behaviour) may reduce foraging motivation (Warburton 2003), information transmission, and learning (Dall et al. 1999) among animals. In our study, fish in natural shoals approached the feeder more rapidly after it was placed in the experimental pool, and showed a lower overall shoaling tendency (illustrated by the predominance of smaller groups and lower association strength) than fish in artificial shoals. A short latency to approach a novel object and low shoaling tendency are often used as indicators of boldness when assessing behavioural syndromes in fish (e.g. Budaev 1997, Ward et al. 2004, Brown et al. 2007). The ability (Sneddon 2003) and opportunity (Dugatkin \& Alfieri 2003) for fish to learn a novel task has previously been shown to be enhanced by increased boldness: Bold fish tend to be more successful, learning more rapidly compared with shy fish. Although we cannot distinguish between behavioural types (e.g. differences in boldness or innovativeness, Sih et al. 2004) or differences in anxiety, motivational state or curiosity, our findings are consistent with the idea that associating with natural group-mates generates a reduced perception of danger. 
463 influence risk perception in fishes (Brown 2001). However, this is unlikely to have

464 played a role in the current experiment as both natural and artificial shoals had spent

465 equal amounts of time in captivity and in the test arenas. The reduced perception of

466 danger may instead stem from the familiar social environment experienced by the

467 natural shoals during the course of the experiment. In contrast, individuals in artificial

468 shoals experience an unfamiliar social environment, in addition to the unfamiliar

469 physical environment of the experimental pool. This may cause them to behave in a

470 more risk-averse manner, resulting in lower foraging success than fish in natural

471 shoals. It takes 12 days for familiarity to develop among members of guppy shoals

472 (Griffiths \& Magurran 1997b) and individuals in the artificial shoals (composed 36-40

473 hours before the experiment commenced) may have moved between groups

474 frequently in order to begin the process of familiarisation, resulting in the observed

475 higher and less variable levels of association in artificial compared to natural shoals.

476 The effect of the social environment is one factor that has previously been shown to

477 influence individual performance in tests of boldness (Griffiths et al. 2004, Sih \&

478 Watters 2005). Bhat \& Magurran (2006) found that individual guppies emerged more

479 quickly from a refuge in the presence of a familiar partner than they did when paired

480 with an unfamiliar partner, suggesting a role for familiarity in determining perception

481 of risk or levels of boldness. Enhanced foraging success and improved learning

482 performance are also linked to familiarity (Swaney et al. 2001, Griffiths 2003, Ward

483 \& Hart 2003, Griffiths et al. 2004, Ward \& Hart 2005). Our work suggests that one

484 underlying mechanism for the increased foraging success of familiar shoals may be

485 reduced perception of risk. 
A second potential explanation for the relative success of natural shoals is that they exhibited higher levels of social learning of the route to the food source. This hypothesis is supported by the observation that entries to the feeder were clustered in time, and that levels of following in natural shoals were somewhat elevated in

491 comparison to artificial shoals. However, clustering was evident in both natural and 492 artificial shoals, and the proportions of individuals first entering the feeder by 493 following were similar. One factor known to influence the level of social learning is 494 the 'conformity effect' (positive frequency-dependent social learning) mediated by 495 shoaling patterns (Day et al. 2001; Brown \& Laland 2001). We found that in natural 496 shoals, groups within the shoal were smaller than those in artificial shoals. Day et al. 497 (2001) found that although individuals in larger groups are on average generally more 498 successful at locating food than individuals in smaller groups, individuals in smaller 499 groups can find a resource more quickly when the resource is hidden. Day et al. 500 (2001) attributed this to a greater reluctance on the part of individuals to leave larger 501 than smaller groups. In our study, the feeder was opaque, thus, in order for a fish to 502 enter and feed it needed to break visual contact with the rest of the shoal. Therefore, 503 individuals in artificial shoals may have been more reluctant to leave their larger 504 groups and enter the feeder than individuals in natural shoals. Alternatively, the more 505 a shoal subdivides into smaller groups, the greater the chance that any single 506 individual will find a hidden resource. This high level of subdivision may be due to 507 lower levels of risk aversion linked to the familiar social environment.

A further hypothesis to explain the relative success of natural shoals is related 510 to the prioritisation of different activities in the different shoal types. Individuals in 511 artificial shoals may prioritise learning about each other (i.e. the process of 
512 familiarisation) over immediate foraging, given the benefits associated with

513 familiarity (Griffiths 2003, Ward \& Hart 2003). Larger group sizes, higher association

514 strengths and lower variation in associations in artificial shoals compared to natural

515 shoals support the idea that individuals are switching associations rapidly as part of

516 this process.

517

518 Information Transmission Within Shoals

519 Previous work has suggested that individuals benefit by learning more rapidly

520 from familiar than unfamiliar shoal mates (Lachlan et al. 1998, Swaney et al. 2001),

521 as fish in familiar groups are more likely to follow one another, leading to an increase

522 in social learning of novel tasks (Swaney et al. 2001). We found evidence that fish

523 followed one another into the feeder, and that association patterns were consistent

524 over time, allowing us to investigate the links between associations and following

525 patterns. However, despite our finding that association patterns before the foraging

526 trial could be used to predict associations after the foraging trial, associations during

527 foraging could not be predicted by previous association patterns. Neither could we

528 find any evidence that individuals specifically followed close associates. Thus, we

529 were unable to find any evidence that information was transmitted along strong ties in

530 natural shoals. However, to our knowledge this is the first time a social networks

531 approach has been used to study patterns of potential information transmission.

532

533 There may be several explanations for our findings. Firstly, individuals may

534 choose their social partners differently from the way they choose their foraging

535 partners. Individuals may, for example, benefit by foraging with those that they know

536 to be poor foragers (Metcalfe \& Thompson 1995), rather than with those that are 
preferred associates in other contexts (e.g. predator inspection, Croft et al. 2006).

538 Secondly, our method of establishing the social and foraging ties may have been

539 inadequate, although it has been previously found to be sufficient to quantify the non-

540 random structure of such groups (Croft et al. 2004 online supplementary material).

541 Thirdly, our power to detect an effect may be reduced by the presence of random

542 interactions creating 'noise' around the non-random preferred interactions.

A fourth possibility is that information may spread via local (Thorpe 1956) or stimulus (Spence 1937) enhancement, where the activity of an individual draws the attention of an observer towards a particular location or object. Information is

547 therefore scrounged by naïve individuals at distance, rather than acquired through

548 close dyadic transmission. Although individuals were unable to see shoal-mates while 549 they were foraging, they may have been able to detect successful foragers after they 550 emerged from the feeder (Lachlan et al. 1998), or the presence of individuals near the 551 feeder may have facilitated movement towards it by naïve individuals. Individuals 552 may therefore have learnt the task from any other individual in the shoal, rather than 553 those with which they were strongly associated. Such exploitation of social 554 information has been demonstrated experimentally in fish (Ward \& Hart 2003). 555 However, information is more likely to be scrounged from close by than from further 556 away, and one might still expect patterns of foraging to be linked to association 557 patterns. Finally, we cannot rule out the possibility that the task used in this experiment 560 was easily learned asocially by individual fish, and consequently did not require social 561 information for its solution. The movement of odour cues may have facilitated this, 
although they are likely to have been well contained (Laland, K. N. unpublished data), particularly without water movement to disperse them (Vogel 1994). Experiments

564 using similar tasks, where individuals learn the route to a foraging resource, have 565 provided evidence for social learning (Reader et al. 2003), and we found evidence that 566 individuals entered the feeder in small groups, suggesting foraging was a social 567 activity. Studies where inexperienced individuals are unlikely to learn the task 568 themselves provide the most compelling evidence for social learning (Lefebvre \& 569 Palameta 1988), thus individuals within a shoal could be trained in a more complex 570 task (e.g. Reader \& Laland 2000, Stanley et al. in press), and the links between social 571 structure and foraging patterns investigated.

Further work is clearly needed to demonstrate whether reduced risk

574 perception, social learning or a further explanation underlies the improved foraging 575 success of natural groups. Evidence is growing for variation in behavioural types 576 across animal species (Sih et al. 2004), and the methodology available for assessing 577 boldness and other traits is increasing, providing the opportunity to assess individual 578 behavioural types in relation to social environment and performance in novel tasks. Social network techniques provide the ideal opportunity for investigating the 581 relationship between group structure, innovation and the diffusion of information or 582 learned behaviours (Latora \& Marchiori 2001). We demonstrate that differences exist 583 between natural and artificial shoals in terms of their social structure, but although 584 these differences may have influenced the effectiveness of information transmission, 585 our investigation found no direct links between social structure and patterns of 586 learning within shoals. Further investigation may reveal a more subtle relationship 
between social structure and patterns of information transfer, and we hope our study encourages this.

\section{ACKNOWLEDGEMENTS}

591 We would like to thank Ronnie Hernandez and the Asa Wright Nature Centre for their 592 continued support in Trinidad. We would also like to thank Dick James and David 593 Mawdsley for assistance with social network analysis and insightful discussions.

594 Funding was provided by the Leverhulme Trust, the EPSRC, ASAB and the FSBI. 595 The experiments presented here comply with the laws of the country in which they 596 were carried out.

\section{REFERENCES}

599

600 Barber, I. \& Ruxton, G. D. 2000. The importance of stable schooling: do familiar 601 sticklebacks stick together? Proceedings of the Royal Society of London, Series B, 602 267, 151-155.

603

604 Barber, I. \& Wright, H. A. 2001. How strong are familiarity preferences in shoaling 605 fish? Animal Behaviour, 61, 975-979.

606

607 Behringer, D. C., Butler, M. J. \& Shields, J. D. 2006. Avoidance of disease by 608 social lobsters. Nature, 44, 421-421.

609 
610 Benjamini, Y. \& Hochberg, Y. 1995. Controlling the False Discovery Rate: a

611 practical and powerful approach to multiple testing. Journal of the Royal Statistical

612 Society Series B, 57, 289-300.

613

614 Bhat, A. \& Magurran, A. E. 2006. Benefits of familiarity persist after prolonged

615 isolation in guppies. Journal of Fish Biology, 68, 759-766.

616

617 Brown, C. 2001. Familiarity with the test environment improves escape responses in 618 the crimson spotted rainbowfish, Melanotaenia duboulayi. Animal Cognition 4,109619113.

620

621 Brown, C. \& Laland, K. N. 2001. Social learning and life skills training for hatchery 622 reared fish. Journal of Fish Biology, 59, 471-493.

624 Brown, C. \& Warburton, K. 1999. Social mechanisms enhance escape responses in 625 shoals of rainbowfish, Melanotaenia duboulayi. Environmental Biology of Fishes, 56, $626 \quad 455-459$

628 Brown, C., Jones, F. \& Braithwaite, V.A. 2007. Correlation between boldness and 629 body mass in natural populations of the poeciliid Brachyrhaphis episcope. Journal of 630 Fish Biology, 71, 1590-1601

631

632 Budaev, S. V. 1997. "Personality" in the guppy (Poecilia reticulata): A correlational 633 study of exploratory behavior and social tendency. Journal of Comparative 634 Psychology, 111, 399-411. 
636 Bull, C. M., Griffin, C. L., Lanham, E. J. \& Johnston, G. R. 2000. Recognition of 637 pheromones from group members in a gregarious lizard, Egernia stokesii. Journal of 638 Herpetology, 34, 92-99.

639

640 Cadieu, N. \& Cadieu, J. C. 2004. The influence of free interactions and partner 641 familiarity on social transmission in the young canary. Animal Behaviour, 55, 10516421057.

644 Chivers, D. P., Brown, G. E. \& Smith, R. J. F. 1995. Familiarity and shoal cohesion 645 in fathead minnows (Pimephales promelas): implications for antipredator behaviour. 646 Canadian Journal of Zoology, 73, 955-960.

648 Clarke, D. C., Beshrea, D. D. \& Moore, A. J. 1995. Role of familiarity in 649 structuring male-male social interactions in the cockroach Gromphadorhina 650 portentosa (Dictyoptera, Blaberidae). Annals of the Entomological Society of 651 America, 88, 554-561.

654 Krause, J. 2003b. Sex biased movement in the guppy (Poecilia reticulata).

655 Oecologia, 137, 62-68.

656

657 Croft, D. P., Arrowsmith, B. J., Bielby, J., Skinner, K., White, E., Couzin, I. D., 658 Magurran, A. E., Ramnarine, I. \& Krause, J. 2003a. Mechanisms underlying shoal 659 composition in the Trinidadian guppy, Poecilia reticulata. Oikos, 100, 429-438. 
661 Croft, D. P., James, R., Thomas, P. O. R., Hathaway, C., Mawdsley, D., Laland,

662 K. N. \& Krause, J. 2006. Social structure and co-operative interactions in a wild 663 population of guppies (Poecilia reticulata). Behavioral Ecology and Sociobiology, 59, $664 \quad 644-650$.

665

666 Croft, D. P., Krause, J. \& James, R. 2004. Social networks in the guppy (Poecilia 667 reticulata). Proceedings of the Royal Society of London, Series B (Suppl), 271, 516668519.

669

670 Dall, S. R. X., McNamara, J. M. \& Cuthill, I. C. 1999. Interruptions to foraging and 671 learning in a changing environment. Animal Behaviour, 57, 233-241.

672

673 Day, R. L., Macdonald, T., Brown, C., Laland, K. N. \& Reader, S. M. 2001.

674 Interactions between social size and conformity in guppy social foraging. Animal

675 Behaviour, 62, 917-925.

676

677 Dugatkin, L. A. \& Alfieri, M. S. 2003. Boldness, behavioral inhibition and learning. 678 Ethology, Ecology and Evolution, 15, 43-49.

679

680 Galef, B. G. \& Giraldeau, L. -A. 2001. Social influences on foraging in vertebrates:

681 causal mechanisms and adaptive functions. Animal Behaviour, 61, 3-15.

682 
Behaviourally specific preferred associations in bottlenose dolphins, Tursiops spp.

687 Griffiths, S. W. 2003. Learned recognition of conspecifics by fishes. Fish and 688 Fisheries, 4, 256-268

689

Griffiths, S. W., Brockmark, S., Hojesjo, J. \& Johnsson, J. I. 2004. Coping with 691 divided attention: the advantage of familiarity. Proceedings of the Royal Society of 692 London, Series B, 271, 695-699.

693

Griffiths, S. W. \& Magurran, A. E. 1997a. Schooling preferences for familiar fish 695 vary with group size in a wild guppy population. Proceedings of the Royal Society of 696 London, Series B, 264, 547-551.

697

Griffiths, S. W. \& Magurran, A. E. 1997b. Familiarity in schooling fish: How long 699 does it take to acquire? Animal Behaviour 53, 945-949.

700

Griffiths, S. W. \& Magurran, A. E. 1998. Sex and schooling behaviour in the

702 Trinidadian guppy. Animal Behaviour 56, 689-693.

703

704 Krause, J. \& Godin, J. -G. J. 1994. Influence of parasitism on the shoaling behavior 705 of banded killifish, Fundus diaphanus. Canadian Journal of Zoology, 72, 1775-1779. 

Press.

Lachlan, R. F., Crooks, L. \& Laland, K. 1998. Who follows whom? Shoaling

711 preferences and social learning of foraging information in guppies. Animal Behaviour, $712 \quad \mathbf{5 6}, 181-190$.

713

714 Laland, K. N. \& Reader, S. M. 1999a. Foraging innovation in the guppy. Animal 715 Behaviour, 57, 331-340.

716

717 Laland, K. N. \& Reader, S. M. 1999b. Foraging innovation is inversely related to 718 competitive ability in male but not in female guppies. Behavioral Ecology, 10, 270719274

Latoria, V. \& Marchiori, M. 2001. Efficient behaviour of small-world networks. Physical Review Letters, 8791, art no 198701.

Lefebvre, L. \& Palameta, B. 1988. Mechanisms, ecology and population diffusion of socially learned, food-finding behaviour in feral pigeons. In: Social Learning: Psychological and Biological Perspectives (Ed by T .R. Zentall \& B. G. Jr. Galef), pp 141-164. Erlbaum, Hillsdale, New Jersey. 
733 Magurran, A. E. 2005. Evolutionary ecology: The Trinidadian guppy. Oxford:

734 Oxford University Press.

736 McRobert, S. P. \& Bradner, J. 1998. The influence of body colouration on shoaling 737 preferences in fish. Animal Behaviour, 56, 611-615.

738

739 Metcalfe, N. B. \& Thompson, B. C. 1995. Fish recognise and prefer to shoal with 740 poor competitors. Proceedings of the Royal Society of London, Series B, 259, 207741210.

742

743 Newman, M. E. J. 2003. The structure and function of complex networks. SIAM

744 Review, 45, 167-256.

745

746 Pitcher, T. J., Magurran, A. E. \& Winfield, I. J. 1982. Fish in larger shoals find 747 food faster. Behavioral Ecology and Sociobiology, 10, 149-151.

748

749 Pitcher, T. J. \& Parrish, J. K. 1993. Functions of shoaling behaviour in teleosts. in: 750 Behaviour of Teleost Fishes (Ed by T. J. Pitcher),. pp 363-439. London: Chapman \& 751 Hall.

752

753 Porter, R. H., Desire, L., Bon, R. \& Orgeur, P. 2001. The role of familiarity in the 754 development of social preferences by lambs. Behaviour, 138, 207-219. 
Reader, S. M. \& Laland, K. N. 2000. Diffusion of foraging information in the guppy. Animal Behaviour, 60, 175-180.

758

Reader, S. M., Kendal, J. R. \& Laland, K. N. 2003. Social learning of foraging sites and escape routes in wild Trinidadian guppies. Animal Behaviour, 66, 729-739.

761

Senar, J. C., Camerino, M. \& Metcalfe, N. B. 1990. Familiarity breeds tolerance: the development of social stability in flocking siskins (Carduelis spinus). Ethology, 85, 12-24.

Sih, A., Bell, A. \& Johnson, J. C. 2004. Behavioural syndromes: an ecological and evolutionary overview. Trends in Ecology and Evolution, 19, 372-378.

Sih, A. \& Watters, J. V. 2005. The mix matters: behavioural types and group dynamics in water striders. Behaviour, 142, 1417-1431.

771

Silk, J. B., Altmann, J. \& Alberts, S. C. 2006. Social relationships among adult female baboons (Papio cynocephalus) I. Variation in the strength of social bonds. Behavioral Ecology and Sociobiology, 61, 183-195.

Sneddon, L. U. 2003. The bold and the shy: individual differences in rainbow trout. Journal of Fish Biology, 62, 971-975.

779 Spence, K. W. 1937. Experimental studies of learning and higher mental process in 780 infra-human primates. Psychological Bulletin, 34, 806-850. 
782 Stanley, E. L., Kendal, R. L., Kendal, J. R., Grounds, S. \& Laland, K. N. In press.

783 The effects of group size, rate of turnover and disruption to demonstration on the

784 stability of foraging traditions in fishes. Animal Behaviour

Swaney, W., Kendal, J., Capon, H., Brown, C. \& Laland, K. N. 2001. Familiarity facilitates social learning of foraging behaviour in the guppy. Animal Behaviour, 62,591-598.

Temeles, E. J. (994. The role of neighbours in territorial systems: when are they 'dear enemies'? Animal Behaviour, 47, 339-350.

793

Thomas, P. O. R., Croft, D. P., Morrell, L. J., Davis, A., Faria, J. J., Dyer, J. R. defection during predator inspection affect social structure in wild shoals of guppies? Animal Behaviour, 75, 43-54

798

Thorpe, W. H. 1956. Learning and instinct in animals. Methuen, London.

800

801 Utne-Palm, A. C. \& Hart, P. J. B. 2000. The effects of familiarity on competitive

802 interactions between threespined sticklebacks. Oikos, 91, 225-232.

803

804 Vogel, S. 1994. Life in Moving Fluids. Princeton: Princeton University Press. 
806 Warburton, K. 2003. Learning of foraging skills by fish. Fish and Fisheries, 4, 203-

807215.

808

809 Ward, A. J. W. \& Hart, P. J. B. 2003. The effects of kin and familiarity on

810 interactions between fish. Fish and Fisheries, 4, 348-358.

811

812 Ward, A. J. W. \& Hart, P. J. B. 2005. Foraging benefits of shoaling with familiars

813 may be exploited by outsiders. Animal Behaviour, 69, 329-335.

814

815 Ward, A. J. W. \& Krause, J. 2001. Body length assortative shoaling in the European

816 minnow, Phoxinus phoxinus. Animal Behaviour, 62, 617-621.

817

818 Ward, A. J. W., Thomas, P., Hart, P. J. B. \& Krause, J. 2004. Correlates of

819 boldness in three-spined sticklebacks (Gasterosteus aculeatus). Behavioral Ecology

820 and Sociobiology, 55, 561-568.

821

822 Wolf, J. B. W. 2005. Know your neighbour: socio-spatial structure in a colony of the

823 Galapagos sea lion (Zalophus californianus wollebaeki), Bielefeld, Germany, PhD

824 Thesis.

825

826 
Table 1: Results of the Mantel tests for matrix comparisons and within-shoal foraging

829 foraging trial, b) whether individuals first enter the feeder by following a close

830 associate and c) correlations between social network structure and associations during

831 the foraging trial, for the 10 natural shoals only. $P$-values for significant positive

832 correlations are highlighted in bold, significant negative correlations are marked with

833 an asterisk. Combined P values are the result of Fisher's Omnibus tests (see text for

834 details).

835

836

\begin{tabular}{|c|c|c|c|c|c|}
\hline \multirow[b]{2}{*}{ Shoal } & \multicolumn{2}{|c|}{$\begin{array}{l}\text { a) Is social structure } \\
\text { stable over time? }\end{array}$} & \multirow[t]{2}{*}{$\begin{array}{l}\text { b) Do individuals } \\
\text { follow close } \\
\text { associates? }\end{array}$} & \multicolumn{2}{|c|}{$\begin{array}{l}\text { c) Does social structure } \\
\text { predict foraging } \\
\text { associations? }\end{array}$} \\
\hline & $\begin{array}{l}\text { Correlation } \\
\text { coefficient }\end{array}$ & $P$ & & $\begin{array}{l}\text { Correlation } \\
\text { coefficient }\end{array}$ & $P$ \\
\hline 1 & 0.751 & 0.003 & 0.828 & -0.17421 & 0.746 \\
\hline 2 & -0.092 & 0.683 & 0.848 & -0.19205 & 0.827 \\
\hline 3 & 0.075 & 0.357 & 0.852 & -0.23796 & 0.919 \\
\hline 4 & 0.221 & 0.123 & 0.811 & -0.32566 & $* 0.960$ \\
\hline 5 & 0.018 & 0.462 & 0.432 & 0.188126 & 0.220 \\
\hline 6 & 0.088 & 0.336 & 0.243 & 0.305839 & 0.108 \\
\hline 7 & 0.606 & 0.017 & 0.195 & -0.00192 & 0.517 \\
\hline 8 & 0.627 & 0.002 & 0.249 & 0.495813 & 0.003 \\
\hline 9 & 0.696 & 0.007 & 0.211 & -0.03941 & 0.548 \\
\hline 10 & 0.530 & 0.005 & 0.352 & 0.429002 & 0.078 \\
\hline $\begin{array}{l}\text { Comb- } \\
\text { ined } P\end{array}$ & & $<0.001$ & 0.639 & & 0.111 \\
\hline
\end{tabular}


840 Figure 1: Percentage frequency distributions of guppy groups in natural (open circles)

841 and artificial (filled circles) shoals. Values are the median percentage frequency of

842 individuals in groups of each size across all replicate trials. Error bars represent

843 interquartile range. Solid lines are used as a visual aid only, linking values for each

844 shoal type.

845

846 Figure 2: Comparing median values for network measures (association strength; AS)

847 between natural and artificial shoals. a) shoal AS ( $z=-3.628, N_{\text {natural }}=N_{\text {artificial }}=10$,

$848 P<0.001)$ and b) coefficient of variation in $\mathrm{AS}\left(z=-3.175, N_{\text {natural }}=N_{\text {artificial }}=10\right.$,

$849 P=0.001)$. Error bars indicate the inter-quartile range.

850

851 Figure 3: Results of the foraging trial comparing natural and artificial shoals. a)

852 median time to approach the feeder $\left(z=-2.117, N_{\text {natural }}=N_{\text {artificial }}=10, P=0.035\right)$ and b)

853 the median number of fish feeding in each shoal $\left(z=-3.752, N_{\text {natural }}=N_{\text {artificial }}=10\right.$,

$854 P<0.001)$. Error bars indicate the inter-quartile range.

855

856 Figure 4: Median number of fish in a shoal that first entered the feeder alone (open

857 bars) as opposed to following a demonstrator (closed bars), for both a 5 second and 20

858 second following rule, in natural $(5 \operatorname{secs}: z=-2.501, N=10, P=0.036 ; 20$ secs: $z=-1.279$,

$859 N=10, P=0.201)$ and artificial ( 5 secs: $z=-2.041, N=10, P=0.123 ; 20$ secs: $z=-1.236$,

$860 N=10, P=0.216$ ) shoals. Error bars indicate the inter-quartile range.

861 
864 Figure 1:

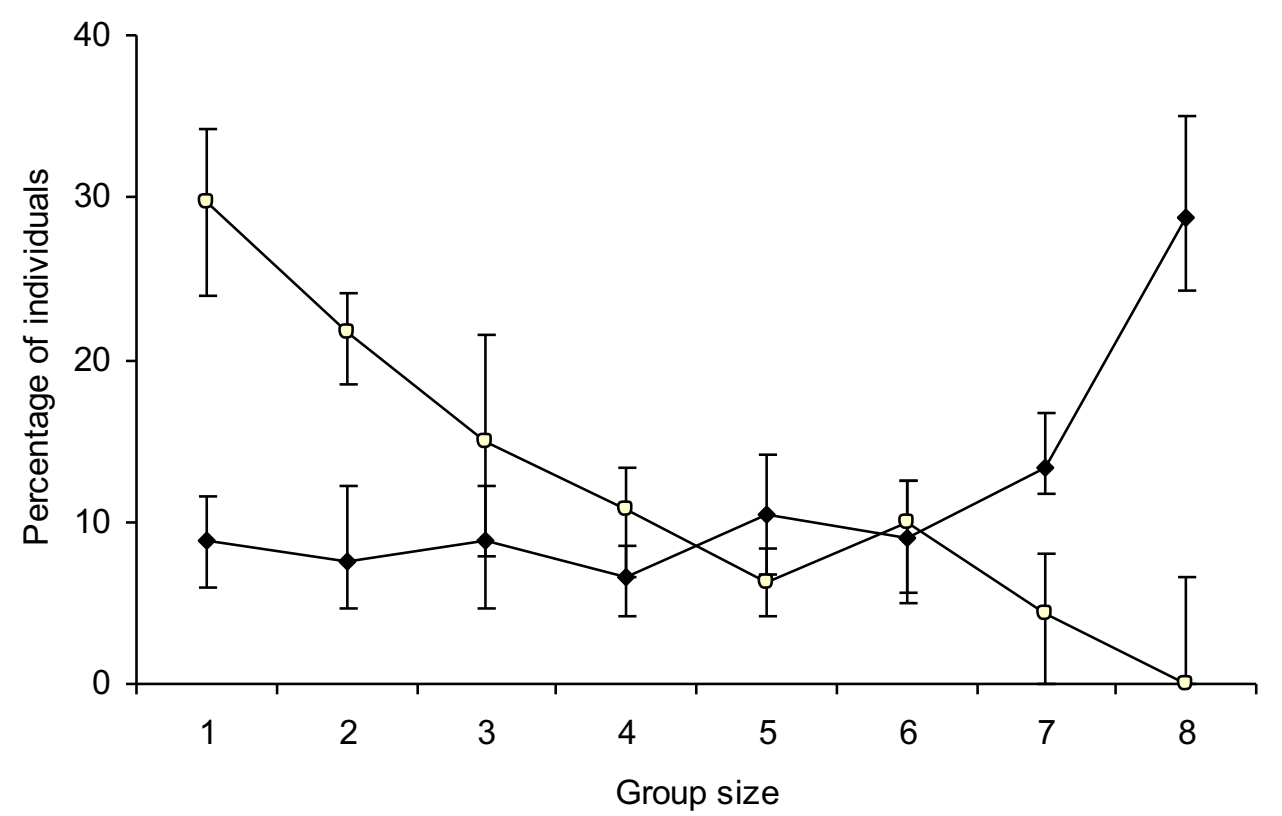

865 
866 Figure 2

867 a)

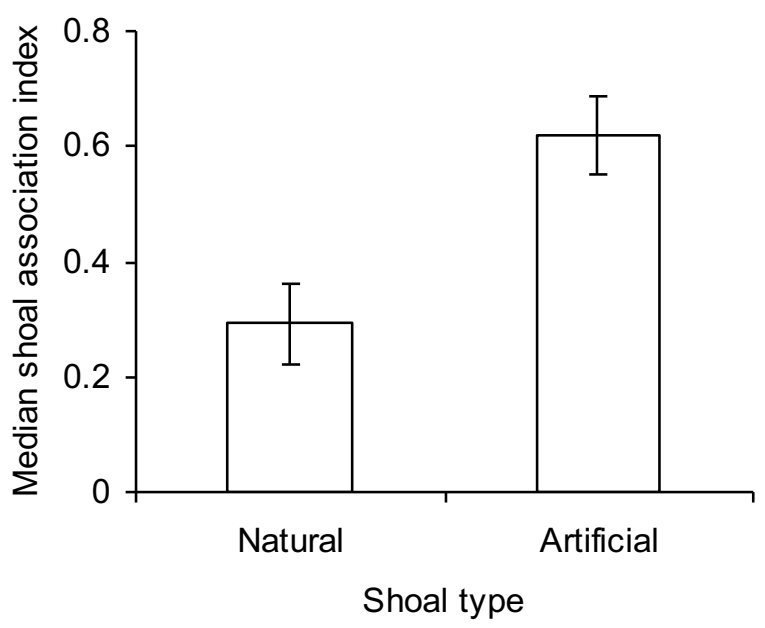

868

869 b)

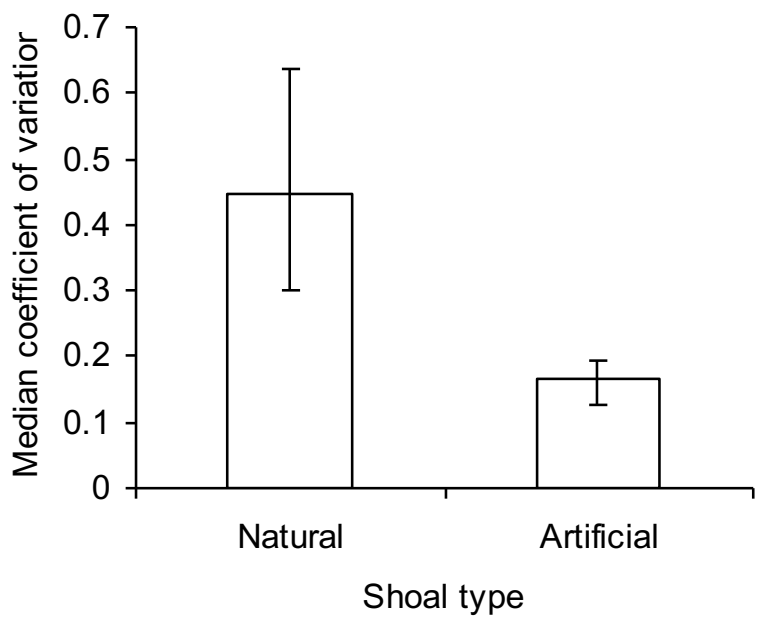

870

871 
$872 \quad$ Figure 3

873 a)

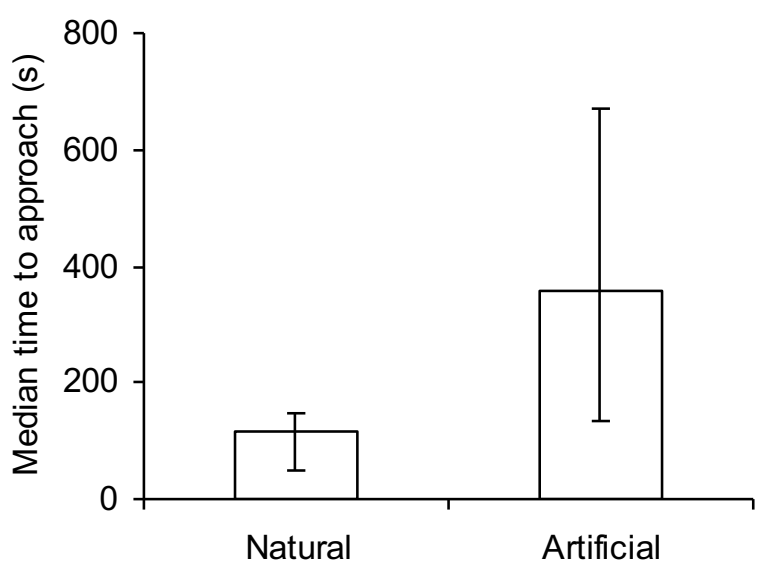

Shoal type

874

875 b)

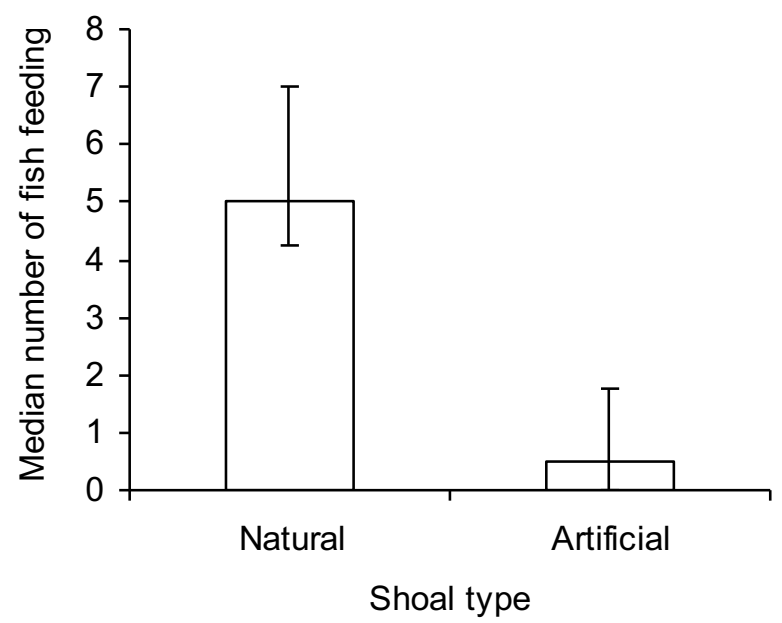

876

877

878 
$879 \quad$ Figure 4

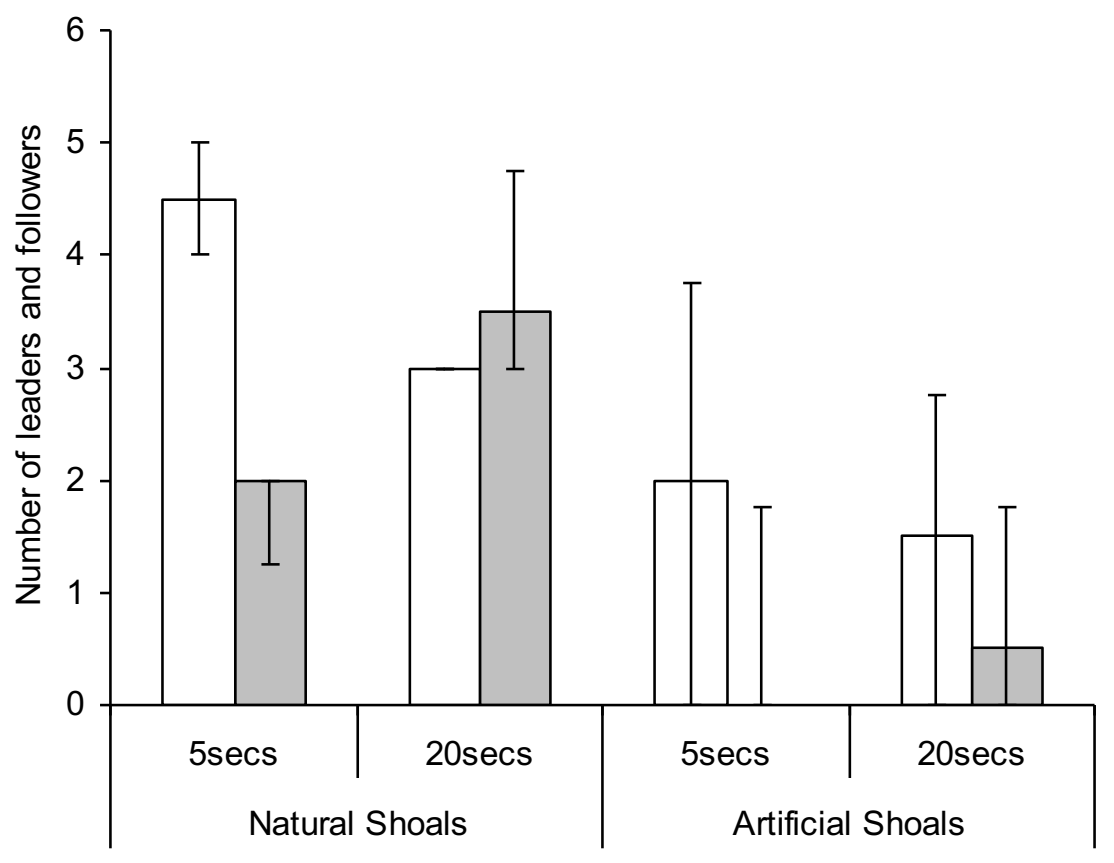

880

881

882 